\title{
Metallomics
}

Cite this: Metallomics, 2014, 6,885

Received 11th December 2013, Accepted 28th January 2014

DOI: $10.1039 / \mathrm{c} 3 \mathrm{mt} 00365 \mathrm{e}$

www.rsc.org/metallomics

\section{Cadmium concentrations in human blood and urine are associated with polymorphisms in zinc transporter genes $\dagger$}

\author{
Gerda Rentschler, ${ }^{a}$ Maria Kippler, ${ }^{b}$ Anna Axmon, ${ }^{a}$ Rubhana Raqib, ${ }^{c}$ \\ Staffan Skerfving, ${ }^{a}$ Marie Vahter ${ }^{\mathrm{b}}$ and Karin Broberg ${ }^{\star a b}$
}

\begin{abstract}
Background. Variation in susceptibility to cadmium (Cd) toxicity may partly be due to differences in $\mathrm{Cd}$ toxicokinetics. Experimental studies indicate that zinc $(Z n)$ homeostasis proteins transport Cd. Objective. To evaluate the potential effect of variation in Zn-transporter genes (SLC39A8 and SLC39A14) on Cd concentrations in blood and urine. Methods. We studied women from the Argentinean Andes [median urinary $\mathrm{Cd}$ concentration $(\mathrm{U}-\mathrm{Cd})=0.24 \mu \mathrm{g} \mathrm{L}^{-1}$; erythrocyte $\mathrm{Cd}\left(\right.$ Ery-Cd) $\left.=0.75 \mu \mathrm{g} \mathrm{L}^{-1}(n=172)\right]$ and from rural Bangladesh [U-Cd $=0.54 \mu \mathrm{g} \mathrm{L}^{-1}(n=359)$, Ery-Cd $=1.1 \mu \mathrm{g} \mathrm{L}^{-1}(n=400)$ ]. Polymorphisms ( $n=36$ ) were genotyped with Sequenom. Gene expression was measured in whole blood with Illumina DirectHyb HumanHT-12 v4.0. Results. Polymorphisms in SLC39A8 and SLC39A14 were associated with Ery-Cd concentrations in the Andean population. For SLC39A14, women carrying GT or TT genotypes of rs4872479 had 1.25 [95\% confidence interval $(\mathrm{Cl})=1.07-1.46]$ times higher Ery-Cd than women carrying GG. Also, women carrying AG or AA of rs870215 had 1.17 (Cl 1.01-1.32) times higher Ery-Cd than those carrying GG. For SLC39A8, women carrying AG or GG of rs10014145 had 1.18 (Cl 1.03-1.35) times higher Ery-Cd than those with AA, and carriers of CA or AA of rs233804 showed $1.22(\mathrm{Cl} 1.04-1.42)$ times higher Ery-Cd than CC. The Bangladeshi population had similar, but statistically non-significant associations between some of these SNPs and Ery-Cd. In the Andean population, the genotypes of SLC39A14 rs4872479 and rs870215 associated with lower Ery-Cd showed positive correlations with plasma-Zn (P-Zn) and SLC39A14 expression. Conclusions. Polymorphisms in SLC39A14 and SLC39A8 seemed to affect blood Cd concentrations, for SLC39A14 this effect may occur via differential gene expression.
\end{abstract}

\section{Introduction}

The widespread toxic element cadmium (Cd) adversely affects kidneys and bones, even at the low exposure levels found in the general population worldwide. ${ }^{1-4} \mathrm{Cd}$ exposure occurs mainly from smoking and from food, such as cereals, vegetables and shellfish. ${ }^{5}$ The intestine absorbs very little Cd, usually less than $5 \%$ of the amount ingested, ${ }^{6}$ but this varies widely. In particular, individuals with low iron stores absorb more $\mathrm{Cd}^{7-9} \mathrm{Cd}$ accumulates in the kidney; therefore, even a small increase in the absorption rate could have severe effects later in life.

\footnotetext{
${ }^{a}$ Department of Laboratory Medicine, Division of Occupational and Environmental Medicine, Lund University, Lund, Sweden

${ }^{b}$ Institute of Environmental Medicine, Unit of Metals and Health,

Karolinska Institutet, 17177 Solna, Stockholm, Sweden.

E-mail: karin.broberg@ki.se; Tel: +46-8-52487407

${ }^{c}$ International Centre for Diarrhoeal Disease Research, Bangladesh (ICDDR,B), Dhaka, Bangladesh

$\dagger$ Electronic supplementary information (ESI) available. See DOI: 10.1039/ c3mt00365e
}

Twin-studies showed that genetic factors influence Cd kinetics in humans, ${ }^{10,11}$ and women showed a more pronounced genetic effect than men. ${ }^{10}$ One study of 370 human volunteers from Thailand found an association of the glutathione S-transferase polymorphism GSTP1 rs1695 and Cd concentrations in blood. ${ }^{12}$ Furthermore, a polymorphism in the metallothionein IIA gene MT2A was associated with differences in Cd concentrations in the human kidney cortex. ${ }^{13}$ We recently showed that one polymorphism in the iron-related transferrin receptor gene TFRC was associated with differences in Cd concentrations in women's urine, a marker of long-term $\mathrm{Cd}$ accumulation in the kidney. ${ }^{14}$

Cd interacts with zinc $(\mathrm{Zn})$ and binds with high affinity to Zn-binding metallothioneins and Zn-finger proteins. ${ }^{15}$ Also, Cd may interact with the $\mathrm{Zn}$ transporters encoded by $S L C 39 A 8$ and SLC39A14, as shown in vitro and in animal experiments. ${ }^{16-18}$ $S L C 39 A 8$ and SLC39A14 are expressed in the intestine and in the kidney, but the role of the encoded proteins in $\mathrm{Cd}$ toxicokinetics in vivo remains unclear.

This study aimed to elucidate whether polymorphisms in SLC39A8 and SLC39A14, belonging to the Zn-homeostasis system, 
modify Cd concentrations in blood and urine. We studied this in two different populations, one in the Argentinean Andes and one in Bangladesh.

\section{Results}

\section{Characteristics of study participants}

Compared with the Andean women, the Bangladeshi women had higher Ery-Cd and U-Cd, but lower BMI, P-Zn and plasma ferritin (Table 1). Using $0.5 \mathrm{mg} \mathrm{L}^{-1}$ as the threshold for adequate/ low Zn concentrations, ${ }^{19}$ only $6 \%$ of the Andean women, but $35 \%$ of the Bangladeshi women had low $\mathrm{Zn}$ concentrations. Ery-Cd and U-Cd were positively correlated with age in both populations (all $p$-values $<0.001 ;$ ESI, $\uparrow$ Table S4). In the Andean women, P-Zn correlated weakly with $\mathrm{U}-\mathrm{Cd}\left(r_{\mathrm{S}}=0.20 ; p<0.05\right)$, age $\left(r_{\mathrm{S}}=0.24 ; p<\right.$ $0.05)$, and parity $\left(r_{\mathrm{S}}=0.25 ; p<0.05\right)$, but not with Ery-Cd. In the Bangladeshi women, P-Zn did not correlate with any of those, but Ery-Cd correlated inversely with ferritin $\left(r_{\mathrm{S}}=-0.18 ; p<0.001\right)$.

For the SNPs rs10014145 and rs233804 (SLC39A8), minor allele frequencies (MAFs) differed more than 20\% between the populations (Table 2, ESI, $\dagger$ Table S1), whereas MAFs of rs4872479 and rs870215 (SLC39A14) did not differ substantially $(<6 \%)$. The SNPs rs10014145, and rs233804 (SLC39A8) were not in linkage disequilibrium (LD) in either population $\left(r^{2}=11\right.$ and $10 \%$, respectively). The SNPs rs4872479 and rs870215 in SLC39A14 were in weak LD in the Andean $\left(r^{2}=66 \%\right)$ but not in the Bangladeshi populations $\left(r^{2}=15 \%\right)$.

\section{Associations of polymorphisms with differences in metal biomarkers}

SLC39A14. In models adjusted for age only, women with the GT or TT genotypes of rs4872479 showed 1.25 (95\% confidence interval [CI] 1.07-1.46) times higher Ery-Cd than women with GG in the Andean, but not in Bangladeshi (1.06 [CI 0.92-1.23]; Table 2) populations. Women with GT or TT also showed nonsignificantly higher U-Cd in both populations (1.21 and 1.17, respectively). Carriers of the AG or AA genotypes of rs870215 had 1.17 (CI 1.01-1.32) times higher Ery-Cd and 1.23 (CI 0.96-1.57) times higher U-Cd in the Andean population, compared to GG carriers. In the Bangladeshi population, we detected a trend of increased Ery-Cd in women with AA (1.12 [CI 0.82-1.58] times higher) and AG genotypes (1.07 [CI 0.96-1.20] times higher) compared with those with GG genotypes ( $p$-value for trend $=0.18$ ). Additionally adjusting the Cd models for P-Zn, parity or BMI did not change the results substantially; i.e., the level of statistical significance remained unaffected and the effect estimates changed by less than \pm 0.05 . Also, adjusting for ferritin affected the estimates very little (less than \pm 0.07 ), except that the association between rs870215 and Ery-Cd became statistically non-significant 1.12 (CI 0.97-1.29).

The SNPs were not statistically significantly associated with differences in P-Zn (Table 2). However, carriers of GT/TT of rs4872479 showed lower ferritin concentrations in both populations, and the difference was statistically significant in the Andean women (Table 2). Homozygote but not heterozygote carriers of rs870215 had higher P-ferritin in the Bangladeshi women. One non-synonymous (rs896378, P33L) and one synonymous (rs2293144, L65L) SNPs were also analyzed. The MAF was sufficient for both SNPs to allow us to calculate associations with differences in Ery-Cd and U-Cd. However, we detected no associations (data not shown).

SLC39A8. The AG or GG carriers of rs10014145 in the Andean women showed 1.18 (CI 1.03-1.35) times higher Ery-Cd, and 1.23 times higher U-Cd (CI 0.97-1.54) compared with AA (Table 2). In the Bangladeshi women, rs10014145 GG carriers showed 1.15 (CI 0.99-1.33; $p$ for trend = 0.04) higher Ery-Cd but not higher U-Cd. The CA or AA carriers of rs233804 in the Andean women showed 1.22 (CI 1.04-1.42) times higher Ery-Cd and 1.34 (CI 1.03-1.76) times higher U-Cd (Table 2). Heterozygote carriers for rs233804 were associated with Ery-Cd in the Bangladeshi population (Table 2). Adjusting the models for P-Zn, parity or BMI did not change the results substantially; the level of significance remained unaffected and the effect estimates changed by less than \pm 0.02 . Also, adjusting for ferritin minimally altered the effect estimates (less than \pm 0.05 ).

One non-synonymous (rs13107325, A391T) and one synonymous (rs17823966, H347H) SNPs were evaluated for association with differences in Ery-Cd or U-Cd; however, the MAF was too low for rs13107325 and for rs17823966 we found no associations (not in table).

The other SNPs of SLC39A8 or SLC3914 (ESI, † Table S1) did not show any statistically significant associations with differences in Ery-Cd, U-Cd or P-Zn.

Table 1 General characteristics of the two groups of women

\begin{tabular}{|c|c|c|c|c|c|c|c|c|c|}
\hline \multirow[b]{3}{*}{ Variable } & \multicolumn{6}{|c|}{ Argentinean Andes } & & & \\
\hline & \multicolumn{3}{|l|}{ All } & \multicolumn{3}{|c|}{ Sub-group $^{a}$} & \multicolumn{3}{|c|}{ Bangladesh } \\
\hline & $N$ & Median & Range & $N$ & Median & Range & $N$ & Median & Range \\
\hline $\operatorname{Age}^{b}$ (years) & 172 & 36 & $12-80$ & 72 & 34 & $12-65$ & 403 & 26 & $14-44$ \\
\hline BMI & 172 & 25 & $16-40$ & 72 & 24 & $16-36$ & 400 & 20 & $14-29$ \\
\hline Parity & 167 & 4 & $0-14$ & 70 & 3 & $0-14$ & 403 & 1 & $0-7$ \\
\hline Cadmium in blood $^{b}\left(\mu \mathrm{g} \mathrm{L}^{-1}\right)$ & 172 & 0.36 & $0.17-1.0$ & 72 & 0.32 & $0.17-1.1$ & - & - & - \\
\hline Cadmium in erythrocytes ${ }^{b, c}\left(\mu \mathrm{g} \mathrm{kg}^{-1}\right)$ & 172 & 0.75 & $0.36-2.1$ & 72 & 0.68 & $0.37-1.9$ & 400 & 1.1 & $0.31-5.4$ \\
\hline Cadmium in urine $^{b, d}\left(\mu \mathrm{g} \mathrm{L}^{-1}\right)$ & 172 & 0.24 & $0.01-1.5$ & 72 & 0.22 & $0.01-1.5$ & 359 & 0.54 & $0.05-4.5$ \\
\hline Zinc in plasma ${ }^{b}\left(\mathrm{mg} \mathrm{L}^{-1}\right)$ & 157 & 0.72 & $0.39-4.8$ & 64 & 0.72 & $0.39-4.8$ & 399 & 0.56 & $0.27-2.1$ \\
\hline Ferritin in plasma ${ }^{b}\left(\mu \mathrm{g} \mathrm{L}^{-1}\right)$ & 166 & 52 & $4-1200$ & 70 & 48 & $4-320$ & 399 & 30 & $2.6-200$ \\
\hline
\end{tabular}

${ }^{a}$ Sub-group included in gene expression analyses. ${ }^{b}$ Figures for Argentinean Andes and U-Cd in Bangladesh were published earlier in Rentschler $e t$ al. ${ }^{14}$

${ }^{c} \mathrm{Cd}$ in erythrocytes calculated in Argentinean Andes, measured in Bangladesh as described in Methods. ${ }^{d}$ Adjusted for specific gravity. 
Table 2 Relative changes in cadmium concentrations in urine ( $U-C d)$ and blood (Ery-Cd) (age-adjusted models), and zinc concentrations in plasma (P-Zn) (unadjusted models) between genotypes of SLC39A14 and SLC39A8. Reference genotype is the most common homozygote in the Bangladeshi women $(\mathrm{Cl}=95 \% \text { confidence interval })^{2}$

\begin{tabular}{|c|c|c|c|c|c|c|c|c|c|c|c|}
\hline Gene & SNP & Population & Genotype & $N$ & Ery-Cd (CI) & $N$ & U-Cd (CI) & $N$ & P-Zn (CI) & $N$ & P-Ferritin (CI) \\
\hline \multirow[t]{9}{*}{ SLC39A14 } & \multirow[t]{4}{*}{ rs4872479 } & \multirow[t]{2}{*}{ Andes } & GG & 144 & 1.0 & 144 & 1.0 & 131 & 1.0 & 139 & 1.0 \\
\hline & & & $\mathrm{GT} / \mathrm{TT}^{b}$ & 24 & $1.25(1.07-1.46)^{c}$ & 24 & $1.21(0.92-1.59)$ & 22 & $1.03(0.92-1.16)$ & 23 & $0.62(0.38-0.99)$ \\
\hline & & \multirow[t]{2}{*}{ Bangladesh } & GG & 337 & 1.0 & 304 & 1.0 & 340 & 1.0 & 301 & 1.0 \\
\hline & & & $\mathrm{GT} / \mathrm{TT}^{d}$ & 50 & $1.06(0.92-1.23)$ & 42 & $1.17(0.91-1.50)$ & 51 & $0.95(0.87-1.05)$ & 41 & $0.90(0.71-1.14)$ \\
\hline & \multirow[t]{5}{*}{ rs870215 } & \multirow[t]{2}{*}{ Andes } & GG & 136 & 1.0 & 136 & 1.0 & 123 & 1.0 & 131 & 1.0 \\
\hline & & & $\mathrm{AG} / \mathrm{AA}^{e}$ & 32 & $1.17(1.01-1.32)^{f}$ & 32 & $1.23(0.96-1.57)$ & 30 & $1.07(0.96-1.19)$ & 31 & $0.88(0.57-1.35)$ \\
\hline & & \multirow[t]{3}{*}{ Bangladesh } & GG & 276 & 1.0 & 246 & 1.0 & 278 & 1.0 & 276 & 1.0 \\
\hline & & & AG & 104 & $1.07(0.96-1.20)$ & 102 & $1.00(0.84-1.20)^{h}$ & 105 & $0.96(0.90-1.03)$ & 103 & $0.83(0.71-0.98)$ \\
\hline & & & $\mathrm{AA}^{g}$ & 9 & $1.12(0.82-1.58)$ & & & 9 & $1.07(0.87-1.32)$ & 9 & $1.68(1.05-2.71)$ \\
\hline \multirow[t]{10}{*}{ SLC39A8 } & \multirow[t]{5}{*}{ rs10014145 } & \multirow[t]{2}{*}{ Andes } & AA & 133 & 1.0 & 133 & 1.0 & 121 & 1.0 & 128 & 1.0 \\
\hline & & & $\mathrm{AG} / \mathrm{GG}^{i}$ & 37 & $1.18(1.03-1.35)^{j}$ & 37 & $1.23(0.97-1.54)$ & 34 & $0.91(0.82-1.00)$ & 36 & $1.15(0.76-1.72)$ \\
\hline & & \multirow[t]{3}{*}{ Bangladesh } & AA & 169 & 1.0 & 148 & 1.0 & 170 & 1.0 & 145 & 1.0 \\
\hline & & & AG & 165 & $1.09(0.98-1.21)$ & 152 & $0.98(0.83-1.17)$ & 165 & $0.97(0.91-1.04)$ & 151 & $0.98(0.83-1.15)$ \\
\hline & & & $\mathrm{GG}^{k}$ & 58 & $1.15(0.99-1.33)$ & 52 & $0.99(0.78-1.27)$ & 58 & $0.99(0.90-1.08)$ & 52 & $0.96(0.76-1.21)$ \\
\hline & \multirow[t]{5}{*}{ rs233804 } & \multirow[t]{2}{*}{ Andes } & $\mathrm{CC}$ & 142 & 1.0 & 142 & 1.0 & 127 & 1.0 & 136 & 1.0 \\
\hline & & & $\mathrm{CA} / \mathrm{AA}^{l}$ & 25 & $1.22(1.04-1.42)^{m}$ & 25 & $1.34(1.03-1.76)$ & 25 & $0.98(0.88-1.10)$ & 25 & $1.34(0.84-2.14)$ \\
\hline & & \multirow[t]{3}{*}{ Bangladesh } & $\mathrm{CC}$ & 166 & 1.0 & 144 & 1.0 & 165 & 1.0 & 142 & 1.0 \\
\hline & & & $\mathrm{CA}$ & 180 & $1.13(1.01-1.25)$ & 168 & $0.99(0.83-1.18)$ & 181 & $0.98(0.91-1.04)$ & 166 & $0.93(0.79-1.09)$ \\
\hline & & & $\mathrm{AA}^{n}$ & 54 & $0.97(0.84-1.13)$ & 47 & $1.02(0.79-1.32)$ & 55 & $0.92(0.84-1.02)$ & 47 & $0.95(0.75-1.20)$ \\
\hline
\end{tabular}

${ }^{a}$ In cases where the frequency of a homozygote genotype was low ( $<8$ individuals), this group was pooled with the heterozygotes. ${ }^{b}$ Minor allele frequency $7 \% .{ }^{c}$ False discovery rate (FDR) adjusted $p$-value $0.057 .{ }^{d}$ Minor allele frequency $7 \% .{ }^{e}$ Minor allele frequency $10 \% .{ }^{f}$ False discovery rate (FDR) adjusted $p$-value $0.08 .{ }^{g}$ Minor allele frequency $16 \% .{ }^{h} p$-Value for 3 genotypes $0.6 ;\left(N_{\mathrm{GG}}=246 ; N_{\mathrm{AG}}=95 ; N_{\mathrm{AA}}=7\right) .{ }^{i}$ Minor allele frequency $13 \% .{ }^{j}$ False discovery rate (FDR) adjusted $p$-value $0.057 .{ }^{k}$ Minor allele frequency $36 \% .{ }^{l}$ Minor allele frequency $8 \% .{ }^{m}$ False discovery rate (FDR) adjusted $p$-value 0.08. ${ }^{n}$ Minor allele frequency $36 \%$.

\section{Associations between gene expression and biomarkers of cadmium, zinc and iron}

To determine whether these SNPs affected gene expression, we measured SLC39A8 and SLC39A14 expression in peripheral blood. CA or AA carriers of rs233804 had statistically significantly lower expression of $S L C 39 A 8$ for one of the expression probes (ESI, $\dagger$ Tables S3 and S5). There was no clear genotypespecific association with expression of SLC39A14.

In the Andean women, the expression of SLC39A14 was positively correlated with P-Zn (Table 3A). When the Andean group was split by the rs4872479 genotype, the GG carriers showed a statistically significant positive correlation of SLC39A14 expression with P-Zn, but there was no correlation for GT (Table 3B). However, for GT carriers, U-Cd was inversely associated with SLC39A14 expression. A similar pattern was observed when the group was split by rs870215: for GG carriers, SLC39A14 expression was correlated with P-Zn, while for AG the expression was inversely associated with U-Cd.

Expression of $S L C 39 A 8$ was not correlated with zinc or $\mathrm{Cd}$ biomarkers (ESI, $\uparrow$ Table S6).

\section{Discussion}

In the present study we found evidence that intronic variants of the Zn-transporter genes SLC39A14 (rs4872479 and rs870215) and SLC39A8 (rs10015145 and rs233804) are associated with the kinetics of $\mathrm{Cd}$. The findings of higher $\mathrm{Cd}$ concentrations among carriers of the rare variants appear to be consistent between the
Table 3 Spearman's rank correlations $\left(r_{\mathrm{S}}\right)$ between concentrations of cadmium in blood (B-Cd, $\left.\mu \mathrm{g} \mathrm{L}^{-1}\right)$, cadmium in urine $\left(\mathrm{U}-\mathrm{Cd}, \mu \mathrm{g}^{-1}\right)$, zinc in plasma $\left(P-Z n, \mathrm{mg} \mathrm{L}^{-1}\right)$, or plasma ferritin $\left(\mu \mathrm{g} \mathrm{L}^{-1}\right)$ on the one hand and expression of SLC39A14 in whole blood on the other. Results are presented in all women (A), and stratified by genotype (B), in the Andean population. $N=$ number of women with samples for gene expression

(A)

\begin{tabular}{lccccc}
\hline & & B-Cd & U-Cd & P-Zn & Ferritin \\
\hline Total expression & $r_{\mathrm{S}}$ & -0.11 & -0.10 & $\mathbf{0 . 2 7}$ & 0.03 \\
& $p$ & 0.4 & 0.4 & $\mathbf{0 . 0 3}$ & 0.8 \\
& $N$ & 72 & 72 & 64 & 70 \\
\hline
\end{tabular}

(B)

\begin{tabular}{lllllll}
\hline Expression by SNP & Genotype & & B-Cd & U-Cd & P-Zn & Ferritin \\
\hline rs4872479 & GG & $r_{\mathrm{S}}$ & -0.09 & -0.003 & $\mathbf{0 . 3 0}$ & 0.08 \\
& & $p$ & 0.5 & 1.0 & $\mathbf{0 . 0 3}$ & 0.6 \\
& & $N$ & 61 & 61 & 54 & 59 \\
& GT & $r_{\mathrm{S}}$ & -0.22 & $-\mathbf{0 . 7 3}$ & -0.13 & -0.26 \\
& & $p$ & 0.5 & $\mathbf{0 . 0 2}$ & 0.8 & 0.5 \\
rs870215 & $N$ & 10 & $\mathbf{1 0}$ & 9 & 10 \\
& & & & & & \\
& GG & $r_{\mathrm{S}}$ & -0.12 & 0.03 & $\mathbf{0 . 3 1}$ & 0.14 \\
& & $p$ & 0.4 & 0.8 & $\mathbf{0 . 0 3}$ & 0.3 \\
& & $N$ & 58 & 58 & $\mathbf{5 1}$ & 56 \\
& AG & $r_{\mathrm{S}}$ & -0.20 & $-\mathbf{0 . 8 2}$ & 0.02 & -0.43 \\
& & $p$ & 0.5 & $\mathbf{0 . 0 0 0 7}$ & 1.0 & 0.1 \\
& & $N$ & 13 & $\mathbf{1 3}$ & 12 & 13
\end{tabular}

two population groups. The associations with SLC39A14 and SLC39A8 and Cd, if confirmed in other populations, could be important to explain variation in Cd toxicity in bone and kidney, in particular in populations where alleles related to 
high Cd concentrations are common. SLC39A14 rs870215 is present in $40-67 \%$ of African populations analysed ${ }^{20}$ and $S L C 39 A 8$ rs10014145 in 36\% of Bangladeshis, 33-36\% in Europeans and $31-40 \%$ in Africans. There were no evident effects of the studied SNPs on P-Zn concentrations; however, in the Andean group we found genotype-specific associations for gene expression of SLC39A14 (rs4871479, rs870215) and P-Zn, suggesting the role of these SNPs in the zinc status.

The associations were stronger in the women from the Argentinean Andes than in the pregnant women from Bangladesh, although the blood Cd concentrations were higher in the latter group. Possibly, the lower zinc and iron status in the Bangladeshi women, as judged by the P-Zn and ferritin concentrations, played a role, but we could not find any clear evidence for that. The Bangladeshi women were also leaner than those in the Andes, but BMI did not modify the associations between genotypes and differences in Cd concentrations, indicating that other nutritional factors did not explain the differences in strength of associations between the study groups. In summary, the differences between the populations (BMI, age, parity, P-Zn and P-ferritin) were mathematically adjusted and did only play a minor role in the associations between SNPs and differences in Cd concentrations. The advantages of comparing these two different populations were (1) each group was homogenous, (2) they represented different levels of $\mathrm{Cd}$ exposure with a wide distribution and (3) there were no other sources of Cd exposure (e.g. industrial pollution or smoking).

Both populations have a well-known exposure to other metals, mainly arsenic. ${ }^{21,22}$ Therefore we have adjusted the statistical models for total urinary arsenic and found that it did not contribute to the associations between SNPs and differences in Cd concentrations. Besides, arsenic metabolism is strongly associated with a very different set of genes, one of which is $A S 3 M T .^{23}$ Therefore the exposure to As did not hinder studying associations of SLC39A8 and SLC39A14 with Cd toxicokinetics.

The fact that the populations live at different altitudes could have played a role. It has been suggested that the genetic factors regulating the metabolism of zinc and iron, both of which are essential for heme synthesis and thus protective against hypoxia, account for a larger fraction of the element concentrations in the body in populations residing at high compared with low altitude. ${ }^{24,25}$ Still, we did not observe a stronger genetic effect on the zinc or iron status in Argentina compared to Bangladesh. It should be mentioned though that SLC39A14 was associated with differences in ferritin concentrations in both populations, a finding that might reflect that SLC39A14 is involved in transport of iron in its non-transferrin bound form to the liver. ${ }^{26}$

We found stronger associations between SNPs and differences in $\mathrm{Cd}$ in blood than in urine. Zinc metabolism has a faster turnover compared to other nutrients because stored pools are very small. ${ }^{27}$ Therefore it seems logical that variation in $\mathrm{Cd}$ biomarkers in connection to $\mathrm{Zn}$ metabolism would be more evident in the short term (B-Cd) than in the long-term (U-Cd) marker. The use of U-Cd concentrations as a marker of kidney damage at low exposure levels is limited by the inter-individual variation in tubular uptake. ${ }^{28}$ SLC39A8 and SLC39A14 are ingoing transporters; therefore their increased expression in kidney proximal tubuli would lead to increased re-uptake of $\mathrm{Cd}$ and consequently reduced release of $\mathrm{Cd}$ into urine. Thus, small changes in re-absorption could conceal increased Cd accumulation in the kidneys for many years before the toxic effects will become apparent.

Some observations were made using gene expression data that were available for a sub-group of the Andean population. The positive correlation between expression of SLC39A14 and $\mathrm{P}-\mathrm{Zn}$ is in accordance with earlier animal studies. ${ }^{29,30} \mathrm{We}$ also found indications that this association was specific for GG carriers of rs4871479 or rs870215. Zn signaling or inflammation increases the expression of SLC39A14, resulting in increased $\mathrm{Zn}$ absorption in the gastrointestinal tract and increased $\mathrm{Zn}$ transfer into cells, e.g. in the liver. ${ }^{29,31}$ Compared to liver, the expression level of $S L C 39 A 14$ in blood is low $^{32}$ and the relationship between gene expression in blood in relation to other tissues needs to be further investigated before firm conclusions can be made. However, we speculate that for $S L C 39 A 14$ rs4872479, the G variant is expressed in response to a need for extra $\mathrm{Zn}$, but not the $\mathrm{T}$ variant as it abolishes a binding site for transcription factors of the CEBP family (regulating DNA repair, immune response and wound repair). The same effect of rs4871479 or rs870215 on expression might reflect the LD between them. As SLC39A14 is an ingoing transporter, expression in kidney proximal tubuli will also contribute to increase in P-Zn but will at the same time lead to decreased U-Cd. We observed no association between SLC39A8 expression and Cd or P-Zn, maybe because we studied blood with low expression of $S L C 39 A 8^{16,31}$ and no further conclusions can be drawn from our data regarding the mechanisms of action of the SNPs in this gene.

\section{Conclusion}

This study suggests that genetic variation in $\mathrm{Zn}$ transporters SLC39A8 and SLC39A14 influences Cd concentrations in human blood, meaning that individuals with a certain genotype of these transporters have higher $\mathrm{Cd}$ concentrations. Genotype-specific gene expression seems to be the mechanism underlying the effect of SLC39A14 SNPs on Cd kinetics. If the same associations between the genotype and differences in Cd concentrations can be found in other populations, these results explain part of the variation in Cd kinetics and toxicity.

\section{Experimental}

\section{Study areas and populations}

For this study we used samples and Cd data collected in two previous cross-sectional studies, involving two different populations, one in the Argentinean Andes ${ }^{33}$ and one in rural Bangladesh. ${ }^{19}$ The Health Ministry of Salta, Argentina, the Ethical Review Committee of ICDDR,B, and the Regional Ethics Committee in Stockholm, Sweden, approved the study. Oral and written informed consents were obtained from all participants. 
Argentinean Andes. The women included were part of a cross-sectional study on health effects of elements in drinking water and food in San Antonio de los Cobres and surrounding villages on the Andean plateau (about $4000 \mathrm{~m}$ above the sea level) in Northwestern Argentina (Table 1). The sampling of blood, urine, and plasma was performed in $2008 .{ }^{33}$ Among the first-degree relatives, we excluded 31 daughters to included mothers; thus, 172 female volunteers remained. Only three of the women smoked tobacco, the water concentrations of $\mathrm{Cd}$ were low $\left(<0.17 \mu \mathrm{g} \mathrm{L}^{-1}\right)$, and this area has no known industrial Cd pollution; therefore, the main source of Cd exposure was the food. ${ }^{34}$ A sub-group of 72 non first-degree relatives were chosen for gene expression analysis among samples that had RNA integrity better than 7.5 (randomly chosen for Cd and Zn biomarker levels). The listed characteristics of the Andean subgroup analysed for gene expression did not differ significantly from the whole population (Table 1), except that they were slightly younger (median 34 vs. 36 years).

Bangladesh. The studied women (Table 1) were part of a longitudinal study on health effects of early-life exposure to environmental pollutants in Matlab, a rural area $53 \mathrm{~km}$ southeast of Dhaka. ${ }^{19,35}$ The women were non-smokers living in an area with no known sources of industrial Cd pollution; thus, as in the Andean population, the Cd exposure was mainly via food. ${ }^{36}$ Samples were obtained in early pregnancy, urine at gestational week 8 (range 4-19) and blood at gestational week 14 (range 9-22). ${ }^{19}$ DNA samples from 403 women were available. Among those, measurements of cadmium in both urine and blood were available for 359 and in blood only for an additional 41 women.

\section{Metal biomarkers}

Cadmium. Cadmium concentration in urine (U-Cd) is an index of the body burden, particularly the concentrations in the kidneys, whereas $\mathrm{Cd}$ in blood (B-Cd) mainly reflects ongoing exposure, with some influence from the body burden., ${ }^{47}$ Erythrocyte-Cd (Ery-Cd; Bangladeshi samples), B-Cd (Argentinean samples) and U-Cd were measured using inductively coupled plasma mass spectrometry (ICPMS; Agilent 7500ce, Agilent Technologies, Tokyo, Japan), with the collision cell in helium mode to avoid interference from molybdenum, as described in detail elsewhere. ${ }^{14,19,34}$ Limit of detection (LOD) for B-Cd was $0.011 \mu \mathrm{g} \mathrm{L}^{-1}$ for samples from the Argentinean Andes and $<0.1 \mu \mathrm{g} \mathrm{\textrm {L } ^ { - 1 }}$ for Bangladeshi erythrocyte samples. LOD for U-Cd was $<0.05 \mu \mathrm{g} \mathrm{\textrm {L } ^ { - 1 }}$ in both populations. All samples contained Cd concentrations above the different LODs. Accuracy was ascertained by reference materials for which the obtained Cd concentrations showed a good agreement with certified or recommended concentrations. ${ }^{9,19}$

To compare the blood Cd concentrations in the two study groups, the whole B-Cd from the Andean group was recalculated to Ery-Cd assuming that $95 \%$ of the $\mathrm{Cd}$ is bound in erythrocytes ${ }^{37}$ and that the density of our erythrocyte preparations was $1.055 \mathrm{~g} \mathrm{~mL}^{-1}$. To account for the volume fractions of erythrocytes and plasma, we used the measured hemoglobin concentration of each woman, divided by $340 \mathrm{~g} \mathrm{~L}^{-1}$ (ref. 38 and 39). The median and range of hemoglobin in this group were $156(90-202) \mathrm{g} \mathrm{L}^{-1}$.
To compensate for variations in the dilution of urine, concentrations were adjusted to the mean specific gravity for each population $\left(1.020 \mathrm{~g} \mathrm{~mL}^{-1}\right.$ in Argentina and $1.012 \mathrm{~g} \mathrm{~mL}^{-1}$ in Bangladesh), measured using a digital refractometer (EUROMEXRD712 clinical refractometer; EROMEX, Arnhem, Holland). Because of major differences in body size and meat intake it was not possible to compare creatinine-adjusted urine concentrations between the two groups of women.

Plasma zinc and plasma ferritin. Plasma $\mathrm{Zn}$ concentrations (P-Zn) in the Andean women were measured by spectrophotometry (accredited method, LOD $0.6 \mu \mathrm{mol} \mathrm{L}{ }^{-1}$, imprecision $<2.7 \%$ ). P-Zn in Bangladeshi women was assessed by atomic absorption spectrophotometry (imprecision $<2.0 \%){ }^{40}$ Ferritin concentrations were analysed by immunoassay (Andean samples) and radioimmunoassay (Bangladeshi samples) as previously reported. ${ }^{14,19}$

\section{Genetic analyses}

Genotyping of single nucleotide polymorphisms. Only a few SNPs in SLC39A8 and SLC39A14 have been shown to affect gene expression or protein function. Moreover, many of the SNPs that alter the coding sequence or may lead to a truncated protein are very rare and, thus, would not be expected to explain a major part of the variation in Cd kinetics. Therefore, we used another strategy and selected SNPs (most of them with no functional information) from those that can tag genetic variation in a larger part of the gene by linkage to other SNPs (so called tagSNPs). TagSNPs were calculated using Haploview (version 4.1) and using data from Hapmap for SLC39A8 and SLC39A14. The threshold of minor allele frequency (MAF) was $5 \%$ based on the MAFs in the Asian Hapmap populations (Han Chinese in Beijing, China and Japanese in Tokyo, Japan), the populations closest to the Bangladeshi at the time of selection of the SNPs. Despite the low MAF, we included one synonymous and one non-synonymous SNPs from each of the two genes according to dbSNP. ${ }^{20}$

DNA was isolated from peripheral blood using the QIAmp DNA Blood Mini kit (QIAGEN, Hilden, Germany) by Swegene's DNA facility at Malmö University Hospital, Malmö, Sweden. Altogether, 39 SNPs were genotyped using Sequenom (San Diego, CA, USA) technology by Swegene's DNA facility at Malmö University Hospital, Malmö, Sweden.

The quality control was as follows: if the call algorithm automatically defined the genotype in at least $90 \%$ of the samples, the quality of the assay was sufficient and the SNP was accepted; if the call algorithm automatically reported a genotype for more than $60 \%$ of the SNPs, the DNA quality was sufficient for a sample to be accepted. This resulted in exclusion of 3 SNPs, while the DNA quality was sufficient for all samples to be included. The final data analysis was thus based on 36 SNPs (ESI, $\dagger$ Table S1).

Bioinformatics using the ElDorado database (version 08-2011) was performed to identify transcription-factor sites that may be affected by SNPs (http://www.genomatix.de/en/index.html; ESI, $\dagger$ Table S2).

RNA collection and gene expression analysis. In a subgroup of 122 women from the Andes (the first women sampled), peripheral blood was collected in PAX tubes (PreAnalytiX GmbH, Hombrechtikon, Switzerland). RNA was extracted and checked 
for quality as described in detail elsewhere. ${ }^{33}$ For the gene expression analysis, 72 non first-degree relatives were chosen among samples that had RNA integrity better than 7.5 (randomly chosen for $\mathrm{Cd}$ and $\mathrm{Zn}$ biomarker levels). For the gene expression analysis, DirectHyb HumanHT-12 v4.0 (Illumina, San Diego, CA, USA) was used, according to the manufacturer's instructions, and the analysis was performed at the SCIBLU laboratory at Lund University. Probes for the gene expression analysis are listed in the ESI, $\uparrow$ Table S3. Filtering of the gene expression data was done using BioArray Software Environment (BASE) in an intensity-dependent manner. Results are presented as relative fluorescence units.

\section{Statistical analysis}

The study groups from the Argentinean Andes and Bangladesh were analysed separately. We tested deviations from Hardy-Weinberg equilibrium by chi-square analysis. Linkage disequilibrium (LD) analysis was performed using Haploview. ${ }^{41}$ Among those SNPs that were in $\mathrm{LD}\left(r^{2}>80 \%\right)$, one was chosen randomly to represent linked groups.

Associations of genotypes with differences in metal concentrations (dependent variables) were analysed using multivariableadjusted linear regression analyses. Initially, all models for Cd were adjusted for age since age was correlated with the Cd biomarkers. Thereafter, we additionally adjusted the Cd models for P-Zn, plasma ferritin, parity and BMI. Associations for genotypes with differences in ferritin and zinc were tested in unadjusted models. To obtain normally distributed residuals, U-Cd and EryCd were naturally $\log (\ln )$ transformed. We present the relative changes $(\%)$ of metal concentrations for a variant genotype compared to the most common homozygote genotype in the largest study population, i.e. the one from the Bangladeshi (reference) population, making it possible to compare the effect in two different populations despite their differences in metal concentrations. In general, each polymorphism was analysed as three genotypes, except when the frequency of a homozygote genotype was too low ( $<8$ individuals); then this group was pooled with the heterozygotes. In total, 19 independent tests were performed for associations between SNPs and differences in metal concentrations (Ery-Cd, U-Cd and P-Zn). We used the false discovery rate (FDR) procedure to adjust for multiple comparisons [R version 2.14.2 (http://www.r-project.org/)] in the Andean group where we had statistically significant findings.

Correlations between metal concentrations and gene expression were made using the Spearman correlation coefficient $\left(r_{\mathrm{S}}\right)$. Relationships between SNPs and gene expression data were analysed by Kruskal-Wallis tests.

All calculations were made using SPSS statistics version 20. "Statistical significance" refers to $p<0.05$ (two-tailed).

\section{Abbreviations}

$\begin{array}{ll}\text { B-Cd } & \text { Blood cadmium concentration } \\ \text { Cd } & \text { Cadmium } \\ \text { Ery-Cd } & \text { Erythrocyte cadmium concentration } \\ \text { MAF } & \text { Minor allele frequency }\end{array}$

$\begin{array}{ll}\text { LD } & \text { Linkage disequilibrium } \\ \text { P-Zn } & \text { Plasma zinc concentration } \\ \text { rs } & \text { Reference SNP ID } \\ \text { SLC39A8 } & \begin{array}{l}\text { Solute carrier family } 39 \text { (zinc transporter), } \\ \text { member } 8\end{array} \\ \text { SLC39A14 } & \text { Solute carrier family 39 (zinc transporter), } \\ & \text { member 14 } \\ \text { SNP } & \text { Single nucleotide polymorphism } \\ \text { U-Cd } & \text { Urinary cadmium concentration } \\ \text { Zn } & \text { Zinc }\end{array}$

\section{Acknowledgements}

This research was supported by the Swedish Council for Working Life and Social Research (FAS; project "METALUND"), Karolinska Institutet, Kungliga fysiografiska sällskapet, EU (FP6; project "PHIME” FOOD-CT-2006-016253). The Bangladeshi samples were part of the MINIMat study, funded by UNICEF, Swedish International Development Cooperation Agency (SIDA), UK Medical Research Council, Swedish Research Council, Department for International Development (DFID), and International Centre for Diarrhoeal Disease Research, Bangladesh (ICDDR,B). The authors declare that they have no actual or potential competing financial interests.

\section{References}

1 X. Chen, G. Zhu, T. Jin, L. Lei and Y. Liang, Environ. Toxicol. Pharmacol., 2011, 32, 46-53.

2 P. M. Ferraro, M. Bonello, A. C. Frigo, A. D’Addessi, A. Sturniolo and G. Gambaro, J. Endourol., 2011, 25, 875-880.

3 A. Engström, K. Michaëlsson, M. Vahter, B. Julin, A. Wolk and A. Åkesson, Bone, 2012, 50, 1372-1378.

4 L. Järup and A. Åkesson, Toxicol. Appl. Pharmacol., 2009, 238, 201-208.

5 I. M. Olsson, I. Bensryd, T. Lundh, H. Ottosson, S. Skerfving and A. Oskarsson, Environ. Health Perspect., 2002, 110, 1185-1190.

6 EFSA, EFSA J., 2009, 980, 1-139.

7 A. Åkesson, M. Berglund, A. Schütz, P. Bjellerup, K. Bremme and M. Vahter, Am. J. Public Health, 2002, 92, 284-287.

8 E. Bárány, I. A. Bergdahl, L. E. Bratteby, T. Lundh, G. Samuelson, S. Skerfving and A. Oskarsson, Environ. Res., 2005, 98, 215-223.

9 M. Berglund, A. Åkesson, B. Nermell and M. Vahter, Environ. Health Perspect., 1994, 102, 1058-1066.

10 L. Björkman, M. Vahter and N. L. Pedersen, Environ. Health Perspect., 2000, 108, 719-722.

11 J. B. Whitfield, V. Dy, R. McQuilty, G. Zhu, A. C. Heath, G. W. Montgomery and N. G. Martin, Environ. Health Perspect., 2010, 118, 776-782.

12 N. Khansakorn, W. Wongwit, P. Tharnpoophasiam, B. Hengprasith, L. Suwannathon, S. Chanprasertyothin, T. Sura, S. Kaojarern, P. Sritara and J. Sirivarasai, J. Toxicol., 2012, 2012, DOI: 10.1155/2012/356126.

13 Z. Kayaalti, G. Mergen and T. Söylemezoğlu, Toxicol. Appl. Pharmacol., 2010, 245, 252-255. 
14 G. Rentschler, M. Kippler, A. Axmon, R. Raqib, E. C. Ekström, S. Skerfving, M. Vahter and K. Broberg, Environ. Health Perspect., 2013, 121, 467-472.

15 A. Hartwig, Antioxid. Redox Signaling, 2001, 3, 625-634.

16 L. A. Lichten and R. J. Cousins, Annu. Rev. Nutr., 2009, 29, 153-176.

17 H. Fujishiro, T. Ohashi, M. Takuma and S. Himeno, Metallomics, 2013, 5, 437-444.

18 D. W. Nebert, M. Gálvez-Peralta, E. B. Hay, H. Li, E. Johansson, C. Yin, B. Wang, L. He and M. Soleimani, Metallomics, 2012, 4, 1218-1225.

19 M. Kippler, E. C. Ekström, B. Lönnerdal, W. Goessler, A. Åkesson, S. El Arifeen, L. Å. Persson and M. Vahter, Toxicol. Appl. Pharmacol., 2007, 222, 221-226.

20 NCBI, Database of Single Nucleotide Polymorphisms (dbSNP). Bethesda (MD): NCBI, National Library of Medicine. dbSNP accession:rs870215, (dbSNP Build ID: 138). Available from: http://www.ncbi.nlm.nih.gov/SNP/.

21 G. Concha, K. Broberg, M. Grandér, A. Cardozo, B. Palm and M. Vahter, Environ. Sci. Technol., 2010, 44, 6875-6880.

22 R. Gardner, J. Hamadani, M. Grandér, F. Tofail, B. Nermell, B. Palm, M. Kippler and M. Vahter, Am. J. Public Health, 2011, 101, S333-S338.

23 K. S. Engström, M. B. Hossain, M. Lauss, S. Ahmed, R. Raqib, M. Vahter and K. Broberg, PLoS One, 2013, 8, e53732, DOI: 10.1371/journal.pone.0053732.

24 C. M. Beall, G. M. Brittenham, K. P. Strohl, J. Blangero, S. Williams-Blangero, M. C. Goldstein, M. J. Decker, E. Vargas, M. Villena, R. Soria, A. M. Alarcon and C. Gonzales, Am. J. Phys. Anthropol., 1998, 106, 385-400.

25 D. Zhou, N. Udpa, R. Ronen, T. Stobdan, J. Liang, O. Appenzeller, H. W. Zhao, Y. Yin, Y. Du, L. Guo, R. Cao, Y. Wang, X. Jin, C. Huang, W. Jia, D. Cao, G. Guo, J. L. Gamboa, F. Villafuerte, D. Callacondo, J. Xue, S. Liu, K. A. Frazer, Y. Li, V. Bafna and G. G. Haddad, Am. J. Hum. Genet., 2013, 93, 452-462.

26 J. J. Pinilla-Tenas, B. K. Sparkman, A. Shawki, A. C. Illing, C. J. Mitchell, N. Zhao, J. P. Liuzzi, R. J. Cousins,
M. D. Knutson and B. Mackenzie, Am. J. Physiol.: Cell Physiol., 2011, 301, C862-C871.

27 J. C. King, Am. J. Clin. Nutr., 2011, 94, 679S-684S.

28 A. Chaumont, M. Nickmilder, X. Dumont, T. Lundh, S. Skerfving and A. Bernard, Toxicol. Lett., 2012, 210, 345-352.

29 R. J. Cousins, Int. J. Vitam. Nutr. Res., 2010, 80, 243-248.

30 J. P. Liuzzi, L. A. Lichten, S. Rivera, R. K. Blanchard, T. B. Aydemir, M. D. Knutson, T. Ganz and R. J. Cousins, Proc. Natl. Acad. Sci. U. S. A., 2005, 102, 6843-6848.

31 S. Jenkitkasemwong, C.-Y. Wang, B. Mackenzie and M. Knutson, Biometals, 2012, 25, 643-655.

32 C. Wu, C. Orozco, J. Boyer, M. Leglise, J. Goodale, S. Batalov, C. L. Hodge, J. Haase, J. Janes, J. W. Huss, 3rd and A. I. Su, Genome Biol., 2009, 10, R130.

33 K. Engström, M. Vahter, S. J. Mlakar, G. Concha, B. Nermell, R. Raqib, A. Cardozo and K. Broberg, Environ. Health Perspect., 2011, 119, 182-188.

34 M. B. Hossain, M. Vahter, G. Concha and K. Broberg, Environ. Health Perspect., 2012, 120, 879-884.

35 M. Kippler, W. Goessler, B. Nermell, E. C. Ekström, B. Lönnerdal, S. El Arifeen and M. Vahter, Environ. Res., 2009, 109, 914-921.

36 M. Kippler, B. Nermell, J. Hamadani, F. Tofail, S. Moore and M. Vahter, Toxicol. Lett., 2010, 198, 20-25.

37 G. Nordberg, K. Nogawa, M. Nordberg and L. T. Friberg, in Handbook on the Toxicology of Metals, ed. B. A. Fowler, G. Nordberg, M. Nordberg and L. T. Friberg, Academic Press, 3rd edn, 2007, 445-486.

38 B. Lundh and A.-K. Öhlin, in [in Swedish] Laurells Klinisk kemi i praktisk medicin, ed. P. Fernlund, G. Fex, A. Hanson, J. Stenflo and B. Lundh, Studentlitteratur, Lund, 6th edn., 1991, pp. 291-349.

39 F. León-Velarde, A. Gamboa, J. A. Chuquiza, W. A. Esteba, M. Rivera-Chira and C. C. Monge, High Alt. Med. Biol., 2000, 1, 97-104.

40 M. Clegg, C. Keen, B. Lönnerdal and L. Hurley, Biol. Trace Elem. Res., 1981, 3, 107-115.

41 J. C. Barrett, Cold Spring Harb. Protoc., 2009, 2009, DOI: 10.1101/pdb.ip71. 